\title{
O ESTATUTO DAS PALAVRAS EM VIEIRA NA EXPRESSÃO DO PROFETISMO
}

\section{Lineide SALVADOR MOSCA ${ }^{1}$}

- RESUMO: O presente estudo objetiva examinar os diversos valores atribuídos ao uso da palavra por Vieira, no que toca às previsões $e$ antevisões da história portuguesa e do mundo da época, como homem sintonizado com o seu tempo. A polêmica entre sebastianistas e joanistas e outros lances políticos de relevo na época ensejam o estudo das modalidades lingüísticas para a expressão da certeza/incerteza (epistêmica), do possível/impossível (alética) e a do dever (deôntica). Ressaltava-se o caráter obrigatório de determinadas ações a serem cumpridas pelo povo lusitano. Para tanto, este deveria julgá-las possíveis e nelas crer. $O$ caráter de promessa que permeia o discurso social da década de 1660 , tendo Vieira como grande porta-voz, aponta o caráter performativo de sua linguagem e também da História. O profetismo na obra de Vieira vem recebendo ultimamente tratamento mais acurado, constituindo alvo de novas investigações. A fundamentação teórica do presente trabalho situa-se no âmbito dos estudos da Argumentação e da Retórica, havendo ainda que considerar a transdisciplinaridade exigida por tais estudos e ditada pela personalidade multifacetária de Vieira como missionário, orador, diplomata, confessor/conselheiro, numa orquestração de vozes.

PALAVRAS-CHAVE: Profetismo. História. Discurso. Linguagem. Argumentação. Retórica. Eficácia.

I Departamento de Letras Clássicas e Vemáculas - Faculdade de Filosofia, Letras e Ciências Humanas-USP 05508-900, São Paulo-SP, Brasil. E-mail: lineide@usp.br. 


\section{Introdução}

A tensão e os conflitos permeiam a obra de Vieira, razão pela qual ele se tornou um espelho de seu tempo, o século XVII, tendo participado dos principais debates em torno dos problemas que afligiam a sociedade de então. Os seus críticos o consideraram a figura culminante de sua nacionalidade, afeito que era a entrar na máquina administrativa que a comandava. Estava, por isso, sempre bem perto do poder e das decisões.

Este quadro inicial já indica por si só o campo propício que constitui a sua vida e a sua obra para a retórica, como ação e como discurso, ou melhor dizendo, para o discurso enquanto ação: espaço de controvérsia, lugar da opinião e da argumentação.

Este fato fica evidente em suas próprias palavras. Veja-se trecho da carta que envia ao Rei, quando lhe escreve da Holanda, para onde fora negociar posições a respeito de questões políticas e financeiras, em especial a situação dos judeus expatriados e o confisco de seus bens. São declarações nas quais ao afeto juntavam-se promessas:

Sua majestade saberá muito cedo por cartas quão leais vassalos tem em Ruão, e quão merecedores de os ter perto de si, e se Deus me leva a seus reais pés, eu prometo a V. Mercês que fique muito mais confirmado no bom ânimo em que o deixei, porque até agora o persuadia com argumentos do discurso, e daqui por diante o poderei fazer com experiências de vista. As cousas grandes não se acabam de repente; hão mister de tempo e todas têm seu tempo. 0 desta parece que é chegado porque vejo concorrerem para ela todas as influências, de que não digo mais, porque isso é papel (Cartas, $\left.1^{\circ}, 92\right)$.

Vieira tinha, portanto, plena consciência dos limites do discurso e de como os contactos pessoais e as experiências locais eram importantes.

Dentro dos aspectos multifacetários da obra vieiriana, que percorre variados gêneros, das cartas aos sermões e aos tratados (OQuinto Império do Mundo, A História do Futuroe os não concluídos Clavis Prophetarume Apologia das coisas profetizadas) e também as suas Defesas peranteo Tribunal do Santo Oficio, escolheu-se para exame um tema constante ao longo da unidade intrínseca de sua vida e obra, a questão do profetismo e dos recursos de que Vieira se serve para transmiti-lo, assim como a sua posição a esse respeito. 


\title{
Profetismo e a questão do gênero
}

Não se pode estabelecer um rígido corte quanto ao gênero no tratamento da questão do profetismo, uma vez que em missivas já tratava ele do assunto. Tal é o caso de Esperanças de Portugal, sob forma de uma carta escrita no Maranhão e que veio a constituir um anteprojeto da História do Futuro. Além disso, Vieira já fazia referências a esse empreendimento em várias cartas suas e também nos próprios sermões. Entre esses, podemos citar o de São Sebastião, em que faz alusões ao sebastianismo e a carta de Vieira ao Bispo do Japão e

que, na verdade, daria margem ao surgimento de $O$ Quinto Império do Mundo. Constitui, pois, o profetismo uma idéia constante a atravessar toda a obra vieiriana, embora de modo mais explícito e sistemático a partir da História do Futuro, prosseguindo na Clavis Prophetarum e na Apologia das coisas profetizadas.

Vieira toma o sentido de profecia dentro de um quadro da História e baseado nos múltiplos exemplos que esta deu ao longo de sua trajetória e procura fundamentar essa noção com provas auridas na Antigüidade e nos tempos modernos. Confira-se o seguinte trecho da História do Futuro (1982, p.143):

\begin{abstract}
Não meteremos porém nesta conta senão aquelas profecias somente que, ou pela santidade de seus autores, aprovados e canonizados pela Igreja, ou por outros fundamentos sólidos da razão, experiência e opinião do Mundo, tenham merecido, no juízo dos prudentes, o nome e veneração de profecias ou predições verdadeiras. A este fim, empregarei grande parte deste presente livro na qualificação do espírito profético que tiveram todos os autores do futuro que nesta História se hão de alegar, por ser este não só o principal, senão o único fundamento de toda sua verdade, e sem o qual vã e imeritamente lhe devemos prometer o crédito que de todos os que a lerem esperamos.
\end{abstract}

Trata-se, do que se depreende, de uma atitude profética, antes de mais nada, com fortes fundamentos e que pudessem ganhar a credibilidade das pessoas, enfim, dos seus destinatários, abarcando o argumento de autoridade das vozes convocadas para confirmação das teses do autor.

Outra forma de unidade que se observa em Vieira, além da que já mencionamos entre vida e obra, está o fato de que nele o missionário e o pensador social são indissociáveis, a visão crítica nunca estando ausente de suas preocupações. Entre estas, localiza-se o seu desejo de criar uma unidade 
luso-brasileira entre a metrópole e a colônia, o que bem exemplificou ao longo de sua jornada, nos múltiplos deslocamentos cá e lá. Para representar esses deslocamentos propõe-se um quadro que indica os principais períodos de sua trajetória:

\begin{tabular}{|c|c|c|c|c|c|}
\hline Portugal & Bahia & Portugal & $\begin{array}{c}\text { Missðes no } \\
\text { Brasil }\end{array}$ & Portugal & Brasil \\
\hline $\begin{array}{c}\text { Nasce em } \\
1608\end{array}$ & $\begin{array}{c}\text { Periodo } \\
\text { religioso } \\
\text { Holandeses } \\
\text { no Brasil }\end{array}$ & $\begin{array}{c}\text { Periodo } \\
\text { político } \\
\text { Restauração } \\
1640 \\
\text { Deslocamentos } \\
\text { locais } \\
\text { Holanda } \\
\text { Roma }\end{array}$ & $\begin{array}{c}\text { Período } \\
\text { missionário } \\
\text { Maranhão e } \\
\text { Pará }\end{array}$ & Desterro & $\begin{array}{c}\text { Morre em } \\
1697\end{array}$ \\
\hline
\end{tabular}

No acompanhamento desses deslocamentos é que se podem notar as mudanças em seu pensamento e atitudes, sobretudo no que toca à interpretação da sociedade colonial e do Novo Mundo e também à sua vocação missionária. Esses dois aspectos estão sempre juntos no pensamento social de Vieira. Bem diferente é a sua interpretação do Novo Mundo em sua volta da Europa em comparação a que tinha anos atrás em sua primeira vinda. Pouco a pouco, foise firmando em Vieira a concepção de que a nação portuguesa estaria destinada a conduzir a Igreja Católica na sua missão de converter os judeus da Europa e os não-cristãos do Novo Mundo. Tanto a nação portuguesa, em seu ethos coletivo, como o grupo de missionários da Companhia de Jesus, deveriam ter ciência dos papéis que iriam cumprir no conjunto de revelações dado a partir das escrituras e que caberia interpretar à luz das necessidades de seu tempo. Havia, entretanto, uma tensão entre o projeto imperial e o empreendimento missionário, que os escritos de Vieira bem retratam em seus sermões e nos escritos proféticos. As palavras revelam esse conflito que ele vivia ao realizar este duplo objetivo: trata-se de expressões antitéticas, oxímoros, inversões, paradoxos que consubstanciam essa luta em diversas frentes.

\section{Fases básicas e o discurso profético}

Pode-se destacar, sob esse prisma, três fases básicas: $1^{\circ}$ conflito entre os missionários jesuítas e os da Ordem na Europa, acerca da conduta para com os índios, sobretudo a alocação de seu trabalho. $2^{\circ}$ Ação de seus opositores e a volta à Europa; $3^{\circ}$ volta ao Brasil pela última vez. Aponta, desta vez, dois 
grupos para o projeto visionário a cumprir: a Coroa e os jesuítas.

Em todas as idas e vindas a que se submeteu, pode-se avaliar qual postura foi predominante na multifacetária vida pública de Vieira, que não declinava facilmente de seus propósitos. $O$ grande estudioso seu e de sua época, José Lúcio de Azevedo, no segundo tomo de História de António Vieira (1931) aponta um Vieira vidente (1662-1668), um Vieira revoltado (1669-1680) e um Vieira vencido (1681-1697). Cremos, entretanto, que o fato de ele ter se dobrado ao Tribunal do Santo Ofício, tal como se dera com Galileu, que abjurou suas teses, não fez dele um derrotado, conforme a História mostrará mais tarde. Interessa-nos também a obra de Azevedo, $A$ Evolução do Sebastianismo, cuja $2^{\mathrm{a}}$ edição data de 1947 , com correções, emendas e atualizações da primeira.

Em sua introdução a The Fire of Tongues António Vieira and the Missionary Church in Brazil and Portugal (1998), Thomas Cohen salienta o fato de que a situação era bem mais complexa e menos previsível do que Azevedo aponta em sua periodização. Num balanço crítico dos trabalhos vieirianos existentes, que inclui não só os comentaristas estrangeiros, mas também os estudiosos brasileiros mais antigos e os recentes, Cohen faz um juízo sereno de toda essa turbulência que envolve a obra e vida do autor.

A literatura sobre os escritos proféticos de Vieira é ainda escassa e requer estudos mais minuciosos, segundo José van den Besselaar em seu livro Antonio Vieira: o Homem, a obra, as idéias (1981, p. 137). A sua edição crítica do Livro anteprimeiro da História do Futuro (1976) constitui uma extraordinária contribuição para a compreensão dos escritos proféticos de Vieira, ao lado de sua não menos importante obra $O$ Sebastianismo- história sumária (1982). Deste mesmo ano é a edição crítica da História do Futuro, precedida dos textos do Livro anteprimeiro, de autoria de Maria Leonor Carvalhão Buescu. Já na década de 90, tem-se a organização e fixação do texto Apologia das coisas profetizadas (1994), empreendida por Adma Fadul Muhama e, da mesma autora, Os autos do processo de Vieira na Inquisição (1995), publicado pouco antes da comemoração do III Centenário da morte de Vieira e exposto no impressionante acervo vieiriano da Biblioteca Nacional de Lisboa, onde se pôde ver os próprios originais dos autos da Inquisição. Conforme se nota, é imprescindível o trabalho crítico e filológico, em se tratando da edição de uma obra como a do Pe. António Vieira.

Cabe citar, pela sua extensão e relevância, os 12 volumes intitulados Obras Escolhidas (1951-1954), valiosos por seus prefácios e notas de António 
Sérgio e Hernani Cidade e deste último a edição da Defesa perante o tribunal do Santo Oficio (1957).

\section{Vieira: linguagem e discurso}

Os problemas existentes no Brasil colônia, de natureza religiosa e social, eram inteiramente novos, sobretudo a questão do índio e de seu lugar numa sociedade colonial, constituindo esta uma questão central no pensamento de Vieira. É evidente que estes problemas não poderiam ser expressos em nenhum vocabulário europeu já estabelecido e mesmo as perífrases não davam conta dos novos aspectos a exprimir. Ocorre ainda que a questão lingüística estava diretamente ligada à interpretação teológica, na dependência de uma exegese dos textos. Havia, pois, a necessidade de uma acomodação da língua.

Não é nosso intento fazer um inventário de todas as técnicas usadas por Vieira no que toca ao uso da palavra, mas lembrar que "as disciplinas da palavra eram os instrumentos privilegiados do conhecimento, pois tudo se escondia no texto", na afirmação de Saraiva, em seu conjunto de ensaios intitulado $O$ discurso engenhoso (SARAIVA, 1996, p.95).

Para o historiador português, o século XVII, na Península Ibérica, é uma continuação da Idade Média, em que o sentido tropológico ou imagético das palavras tinha um grande valor. $O$ discurso engenhoso seria exatamente aquele que, além do procedimento gramatical e etimológico, alia todos os processos pelos quais as palavras dizem muito mais do que significam no contexto. Isto vem reiterar o que foi dito atrás a propósito da interpretação $\mathrm{e}$ da exegese. $O$ autor engenhoso, tal como Vieira, depende das palavras e, ao mesmo tempo, liberta-se delas, fragmentando-as, explicando a sua etimologia, fazendo jogo com elas, disjungindo significante e significado e outros artificios. É nesse sentido que podemos falar em uso poético de sua linguagem, ou seja, enquanto libertação do signo, embora essa linguagem obedeça às regras da língua e de sua formação.

No nível do discurso, entendido como encadeamento, desenvolvimento, fica evidente que a ordem do discurso não é necessariamente uma ordem lógica, razão pela qual Vieira nos fala do discurso do tempo, muito mais do que da razão, daí as noções de passado e de futuro se mesclarem, como o próprio título História do Futuro nos demonstra. Na sua época, discurso era também entendido como raciocínio. Há, entretanto, momentos mesmo em que ele beira o onírico, o fantasmagórico, abolindo a relação com a lógica, mas as palavras não fogem à gramática. Conquanto as leis desta sejam observadas, a polissemia e a ambigüidade possibilitam a evasão do rigor e romper a bi-uni- 
vocidade significante/significado. Veja-se, por exemplo, o jogo de plurissignificação quando Vieira utiliza o termo pena, na acepção de escritura e na acepção de sofrimento.

Sempre apoiado na voz de autoridade bíblica, Vieira compara as línguas de fogo dos apóstolos, tal como aparece em Pentecostes, à situação com que se deparam os jesuítas no Novo Mundo ao entrar em contacto com outras línguas, que caberia conhecer.

É a época em que vai crescendo o sebastianismo já mencionado e em que as trovas de Bandarra eram aplicadas a D. João IV, que se acreditava ressuscitaria para criar o Quinto Império. Eram verdadeiros enigmas e decifrações para explicar as trovas de Bandarra e nelas entram não só a linguagem figurada (a partir de leão, lobo, peçonha, veneno etc.), como também a questão da literalidade, problemas a considerar sobretudo quando os exemplos são bíblicos. Enfim, várias formas de discursos proféticos circulavam na literatura da época: sebastianistas, messiânicos, milenaristas, tendo em comum a promessa de uma redenção coletiva, de um inconformismo de ordem social e política, em última análise, de mudança, de crença no futuro.

\section{$O$ estatuto das palavras e seu uso}

Tomemos os principais fatos ligados ao estatuto das palavras nos discursos proféticos de Vieira, quanto aos seguintes aspectos: 1. a configuração do texto, 2. as modalizações (epistêmicas, aléticas e deônticas), 3. os argumentos, 4. a retórica.

\section{O texto:}

Vieira não escrevia de antemão tudo aquilo que ia dizer ao público, conforme se depreende do sermão inacabado para as exéquias de D.Teodósio. Ele anotava assuntos para serem desenvolvidos segundo a inspiração do momento. Há cláusulas avulsas e apontamentos de citações e referências. Depois, reunia os fragmentos e polia os contornos, retocando aqui e ali. Nem sempre as palavras proferidas seriam aquelas impressas. Abre-se aí um campo propício para a atuação da crítica genética.

\section{As modalizações:}

Vieira modaliza o próprio subtítulo de sua Defesa perante o Tribunal do Santo oficio (1957), como segue, "Representação primeira dos fundamentos \& motivos que tive para me parecer provável o que escrevi acerca do spirito profético de Bandarra, e do mais que se inferir das suas predicçõens".

As palavras-chave vêm em itálico para que se avalie o cuidado que Vieira tinha com as palavras: representação indica que não são as coisas, mas as suas substitutas ou símbolos. 
Em se tratando de profecia, natural é que a modalidade epistêmica da certeza esteja presente no discurso, uma vez que Vieira assim a define na Apologia das coisas profetizadas (1994): "a profecia é uma inspiração ou revelação divina de futuros contingentes, antevendo e prenunciando os sucessos com verdade certa e imóvel". Por outro lado, a profecia requer um crer da parte do destinatário, razão do trabalho persuasório que ela envolve. Uma vez aceita, dela decorre um deverou deveres (modalidade deôntica), no caso, a propagação das idéias assumidas, a defesa de compromissos (levá-los aos que chamavam gentios, critério ao mesmo tempo cultural e religioso). A possibilidade (modalidade alética) também faz parte do quadro descrito, conforme se pôde ver na citação dada (parecer provável).

\section{A argumentação:}

Entre os principais tipos de argumento de que Vieira se serve salientamse o silogismo, o argumento pelo efeito, o argumento pelo exemplo e o argumento por autoridade, já mencionado anteriormente.

O silogismo é o tipo de raciocínio mais freqüente na argumentação de Vieira e aparece muitas vezes sob a forma de entimema, isto é, um silogismo abreviado de que se pode deduzir uma das premissas ausentes. Veja-se que claro exemplo quando, após definir profecia, ele continua silogisticamente: "toda esta definição se verifica em Bandarra e suas predições; logo Bandarra teve verdadeiro espírito de profecia" (1974, p.31).

$O$ argumento pelo efeito desempenha um papel importante nas profecias, pelo seu valor de prova. É ele que vem validá-las e dar-lhes o seu estatuto próprio. Nelas, os tempos do futuro antecipam os do presente, vindo estes como resultado. A atitude de Vieira com relação ao tempo fica bem clara nas seguintes palavras da História do Futuro (1982, p.45): "Eles [antigos gregos e romanos] escreveram histórias do passado para os futuros, nós escrevemos a do futuro para os presentes". Veja-se, a seguir, o subtítulo de uma das partes da Defesa perante o Santo Oficio (1957) e o texto da trova que o ilustra:

Predicçoens de Bandarra confirmadas com o effeito depois da acclamação delRey D.João.

Commendadores, Prelados

Que as Igrejas comeis

Traçareis \& volvereis

Por honra dos três estados

E os mais serão taxados.

Todos contribuirão

averá gram confusão

em toda sorte de estados. 
Entre as formas de futuro, a perifrástica com haver de+infinitivo são abundantes nas predições, acarretando um tipo de compromisso mais acentuado que o futuro simples. Não é sem razão que são chamadas futuros promissivos. Do ponto de vista argumentativo, estas formas funcionam como instrumentos de presença, que estabelecem um pacto com o destinatário, participante da interlocução: "Tal é a História, Portugueses, que vos presento, e por isso na língua vossa" (1982, p.54). Veja-se, a título de exemplo, o final do segundo capítulo da História do Futuro, em que as formas perifrásticas mostram o que acabamos de apontar, podendo-se ainda contrastá-las com o futuro simples. No discurso profético, tais construções adquirem valor performativo, uma vez que fazem parte de discursos proferidos por quem tem o poder de fazê-lo, conferindo-lhes a necessária validade. A sua voz de autoridade depende de quem pode dizê-las e em que circunstâncias tais palavras são legitimadas.

Se se há- de restituir o mundo à sua primitiva inteireza $e$ natural formosura, não se poderá consertar um corpo tão grande, sem dor e sentimento dos membros, que estão fora de seu lugar. Alguns gemidos se hão-de ouvir entre vossos aplausos, mas também esses fazem harmonia, se são dos inimigos. Para os inimigos será a dor, para os êmulos a inveja, para os amigos e companheiros o prazer e para vós, então, a glória, e entretanto as Esperanças (1982, cap.II, p. 54-55).

O argumento pelo exemplo é um recurso que o autor considera como a prova por excelência. Na História do Futuro ele se serve abundantemente desse expediente, como se dá na comparação das épocas, em que põe em relevo o valor de seu tempo. Recorre, assim, à história greco-latina (Platão, Aristóteles, Cícero), à história bíblica do Velho e do Novo Testamento, à Idade Média e ao classicismo, demonstrando que conhece a história em sua totalidade.

Após um longo parágrafo, em que mostra como Alexandre Magno se baseava nas profecias do profeta Daniel, Vieira escreve:

Os exemplos que temos domésticos desta mesma utilidade, não são menos admiráveis que estranhos, assim nas batalhas, como nas conquistas (id., cap.VI, p.88).

Defendendo-se das acusações que corriam a respeito das novas profecias, que não eram em absoluto novas, segundo ele, mas tinham respaldo em toda a história precedente, faz uma apologia do novo, da novidade: 
Não é o tempo, senão a razão, a que dá o crédito e autoridade aos escritos; Nem se deve perguntar "quando" escreveram, senão "quam bem" (id., Cap.XI, p. 163).

[...] Não se podia explicar com mais clara comparação nem provarse com mais eficaz argumento, e desde aquele tempo (que foi pelos anos de mil e trezentos) a esta parte, se tem confirmado pela grandeza e liberalidade de Deus em todos os séculos, com mais repetidos exemplos que nos passados... (1982, Cap. XI, p.169)

\section{A retórica:}

Vieira insiste nas regras baseadas naquelas seguidas pelos profetas nas Sagradas Escrituras, conforme se vê na Defesa perante o Santo Oficio, em que procura caracterizar o que é e como se faz para exprimir uma profecia:

"Regra 1a: Quando o profeta diz que vê o sucesso que conta, he certo que he profecia absoluta, ou que infallivelmente há de succeder. 2a Quando o modo \& asseveração com que o profeta conta \& affirma as couzas que ainda estão por cumprir, he o mesmo com que contou \& affirmou as que já estão cumpridas, também então he sinal certo que as ditas profecias não cumpridas se hão de cumprir \& ter seu efeito, assy como as outras o tiveram, porque em humas \& outras corre igualmente a mesma razão" (1957 v.1 p.176-177).

Ao comentar a ocorrência de figuras de animais que simbolizam Reinos e personagens da história eclesiástica (leão, cordeiro, serpente, dragão), Vieira faz algumas considerações sobre estilo: "mas de tudo temos exemplos nos profetas canônicos, que he certo fallavão pello estilo com que Deos lhes fallava... Assy que variar o symbolo ou a figura não he contra o stilo dos verdadeiros profetas" (id., v.1, p.73)

Enfim, Vieira subordina tudo, em última análise, à "eficácia \& energia dos seus argumentos", ou seja, o estilo estaria a serviço dos seus objetivos, que ele formula muito claramente:

os quaes [argumentos], negada a dita verdade \&e a de nossa conclusão, não só ficariam enfraquecidos \& sem effeito, como fica dito, mas também a mayor \& melhor partedo uzo das profecias (que heconvencer com ellas a contumácia dos infiéis) se frustraria, \& a esperança \& consolação dos fieis, em muitas cousas de grande importancia, ficaria duvidosa" (id., v.1, p.177-178). 
Também na História do Futuro vê-se por que o seu texto é claramente persuasivo e o próprio Vieira o declara ao longo do desenvolvimento da obra, o que o cap. VIII reproduz de forma cabal, quando trata do domínio espanhol e de como ele foge à obediência divina:

Isto é, pois, o que eu agora lhes quero persuadir e admoestar, e um dos principais fins por que escrevo esta "História", para que, pelo conhecimento dos nossos futuros, possa emendar o engano de suas esperanças presentes. (1982, cap.VIII)

Todas essas questões estão relacionadas fundamentalmente ao fator credibilidade, que faz intervir o ethos dos implicados, isto é, daquele que faz crer (o persuasor) e daquele que crê (o persuadido).

\section{Vieira e a História}

Outros conceitos entram na concepção de profecia, tais como os de utopia, mito e identidade, assim como o próprio conceito de História. José Gonçalves Salvador (2001) em Vozes da História mostra que nossas crenças e preconceitos são explicados pela História, que é ao mesmo tempo um instrumento de libertação desses preconceitos. Segundo ele, é isto que dá à História o seu sentido altamente humanístico, porque leva à tolerância e impõe responsabilidade.

Vieira mostra a essência da História e, ao mesmo tempo, apresenta os seus limites. Em seu papel de mentor, sente-se abalizado para predizer o futuro e prescrever soluções para a crise presente, valendo-se sempre da intervenção da fé, como homem religioso, faceta que nunca se apaga ao lado do político, diplomata e homem público de seu tempo. Nada mais propício do que a História do Futuro para esse tipo de reflexão, ou seja, no que consiste o fazer história:

A primeira qualidade da história (quando não seja a sua essência) é a verdade; e porque esta parecerá muito dificultosa, e porventura impossível na "História do Futuro" será razão que, antes que vamos mais por diante, sosseguemos o escrúpulo ou receio (quando não seja o riso ou o desprezo) dos que assim a podem imaginar. $\mathrm{E}$ pois pedimos aos leitores o assenso da fé, justo é que lhes mostremos primeiro os motivos da credulidade; não duvidando da pura afeição de todos, pois a matéria é tanto para querer, e tão sua (1982, Cap. IX, p. 137). 
Para Vieira, portanto, o escatológico faz parte integrante da História e supõe as modalidades aléticas do possível/impossível que se cruzam com as epistêmicas do crer (necessidade/contingência) na expressão do discurso profético.

\begin{abstract}
...mostrarei os meios mais prováveis e certos por onde o conhecimento e esperança do futuro Messias não só podia chegar, mas com efeito chegou, ou a todas ou a quase todas as nações de todo o que naquele tempo se chamava Mundo (id., p. 312).Por outro lado, não se pode esquecer que a História já é uma interpretação da interpretação, portanto um segundo grau de conhecimento, nele entrando também a intersubjetividade de seus atores, seus afetos e desafetos. No caso de Vieira, sobretudo nas obras dos últimos períodos, nota-se a confissão de suas frustrações, numa atitude de desabafo e de lamentação.
\end{abstract}

\title{
Considerações finais
}

Toda a polêmica gerada em torno da questão do espírito profético, que desencadeou discursos contrários às posições postuladas por Vieira e seus seguidores, não é isenta de contradições. Delas temos notícias através de documentos trazidos a lume por Besselaar (2002). Essa relação dialética dos discursos é que vem nos indicar o embate que tiveram em seu tempo e redimensioná-los aos leitores de hoje. Nesse sentido é que uma leitura retórica e argumentativa pode trazer uma boa contribuição. A historiografia lingüística, sendo parte desse todo, tem que forçosamente considerar esses aspectos para que os seus registros deixem falar as vozes da História, sobretudo aquelas que ficaram por diversas razões encobertas e mal compreendidas. Esta seria a sua função mais importante.

$\mathrm{Na}$ linha dos discursos históricos portugueses, cabe um lugar relevante aos discursos proféticos, já bem antes das propostas de Vieira em seus diversos escritos dessa natureza. É esse mesmo tipo de discurso que se encontra também em Fernando Pessoa e em autores contemporâneos. É este fio condutor que liga Fernando Pessoa a Vieira, razão de terminarmos essa exposição com um poema de Pessoa que leva o nome do grande mestre de nossa língua, extraído de Mensagem (PESSOA, 1960: 24):

Revista do GEL 20 
António Vieira

0 céu estrela o azul e tem grandeza

Este, que teve a fama e a glória tem,

Imperador da língua portuguesa,

Foi-nos um céu também.

No imenso espaço seu de meditar,

Constelado de forma e de visão,

Surge, prenúncio claro de luar,

El-Rei D.Sebastião.

Mas não, não é luar: é luz e etéreo.

É um dia; e, no céu amplo de desejo,

A madrugada irreal do Quinto Império

Doira as margens do Tejo.

A atitude de esperança, de otimismo presentes nesse percurso fazem parte das utopias que movem as sociedades, havendo sempre uma espera, uma propulsão que as fazem emergir mesmo nos momentos mais difíceis de sua história.

\section{Statute of Vieira's words in the prophetism expression}

- ABSTRACT: This work examines diverse values attributed to Vieira's word use, regarding previsions and foresights of Portuguese and worldwide History in the epoch, as a man connected to his time. The polemic between sebastianistas and joanistas, as well as other political occurrences in his time, gave opportunity for the study of linguistic modalities in order to express the certitude/incertitude (epistemic), the possibility/impossibility (alethic), and the obligation (deontic). The obligatory character to determined action to be accomplished by Lusitanian people was hilghlighted. To get it, Lusitanians should consider them possible, and thrust them. The promise character, which pervades the social discourse from the 1660 s, with Vieira having the status of a notable spokesman, indicates the performative character of his language and of the History. Nowadays the prophetism in Vieira's work receives more accurate treatment, constituting a target of new investigations. The theoretical foundation of this paper is placed in Argumentation and Rhetorical ambit, having 
still to be considered the transdisciplinarity demanded by such studies and dictated by viera's multifarious personality as missionary, orator, diplomate, confessor/counsellor, in an orchestration of voices.

KEYWORDS: Prophetism. History. Discourse. Language. Argumentation. Rhetoric. Efficacy.

\section{Referências}

AZEVEDO, J. L. de. História de António Vieira. 2. ed. Lisboa, $1932,2 \mathrm{v}$.

1947.

. A Evolução do Sebastianismo. 2. ed. Lisboa: Clássica,

BESSELAAR, J. van den. Livro anteprimeiro da história do futuro. Munster: Aschendorffsche Verlagsbuchhandlung, 1976, 2 v.

António Vieira: o homem, a obra, as idéias. Lisboa: Instituto de Cultura e Língua Portuguesa, 1981.

. O Sebastianismo: história sumária. Instituto de Cultura e Língua Portuguesa, 1987.

EDUERJ, 2002.

António Vieira: profecia e polêmica. Rio de Janeiro:

CIDADE, H.; SÉRGIO, A. Pe. António Vieira. Obras Escolhidas. Lisboa: Sá da Costa, 1953 [v. X. História do Futuro]. 12 v.

COHEN, T. M. The fire of Tongues. António Vieira and the Missionary Church in Brazil and Portugal. Stanford: Stanford University Press, 1998.

PESSOA, F. Mensagem. Obras Poéticas. Rio de Janeiro: Aguilar, 1960.

SALVADOR, J. G. Vozes da História. São Paulo: Humanitas, 2001.

SARAIVA, A. J. História e Utopia. Estudos sobre Vieira. Lisboa: Ministério de Educação e Cultura/ Instituto de Cultura e Língua Portuguesa, 1992. 
Gradiva, 1996.

O Discurso Engenhoso. Ensaios sobre Vieira. Lisboa:

VIEIRA, A. História do Futuro. Introd. Atualização do texto e notas de Maria Leonor Carvalhão Buescu. Lisboa: Imprensa Nacional/Casa da Moeda, 1982.

. Defesa perante o Tribunal do Santo Ofício. Introd. e notas de Hernani Cidade. Salvador: Aguiar \& Souza, 1957, 2 v.

Apologia das Coisas Profetizadas. Org. e fixação do texto de Adma Fadul Muhana. Lisboa: Cotovia, 1994.

\section{OBRAS CONSULTADAS}

MENDES, M. V. A oratória barroca de Vieira. Lisboa: Caminho, 1991.

MOSCA, L. S. Crise e Identidade Nacional em Vieira. In: Terceiro Centenário da Morte do Pe. António Vieira. Congresso Internacional. Acta, v. III. Braga, 1999, p.1683-1693.

PINTO, C. B. As Promessas da História. Discursos Proféticos e Assimilação no Brasil Colonial (1500-1700). São Paulo: EDUSP, 2003. 